\title{
CORRECTION
}

\section{Correction to: Beating vibration phenomenon of a very large floating structure}

\author{
Hisayoshi Endo ${ }^{1}\left[\right.$ Hideyuki Suzuki $^{2}$
}

Published online: 26 March 2018

(c) JASNAOE 2018

\section{Correction to: Journal of Marine Science and Technology https://doi.org/10.1007/s00773-017-0502-6}

In the original publication, section numbers "5.4 and 5.4.1" are incorrectly arranged. The corrected section numbers are listed with section subtitles in this Correction.

5.3.3 In the case of the beating vibration accompanied by the higher order free vibration modes

5.3.4 The effect of the drag force

The original article can be found online at https://doi.org/10.1007/ s00773-017-0502-6.

Hisayoshi Endo

hisayoshi_endo@hotmail.com

1 Formerly, National Maritime Research Institute, 6-38-1

Shinkawa, Mitaka-city, Japan

2 Department of Ocean Technology, Policy, and Environment, Graduate School of Frontier Sciences, The University

of Tokyo, Tokyo, Japan 